\title{
Impacts of Wear and Geometry Response of the Cutting Tool on Machinability of Super Austenitic Stainless Steel
}

\author{
Mohanad Alabdullah, Ashwin Polishetty, and Guy Littlefair \\ School of Engineering, Deakin University, 75 Pigdons Rd, Waurn Ponds, VIC 3216, Australia \\ Correspondence should be addressed to Mohanad Alabdullah; mfalabdu@deakin.edu.au
}

Received 8 July 2016; Revised 12 September 2016; Accepted 27 September 2016

Academic Editor: Rene Romero-Troncoso

Copyright ( 2016 Mohanad Alabdullah et al. This is an open access article distributed under the Creative Commons Attribution License, which permits unrestricted use, distribution, and reproduction in any medium, provided the original work is properly cited.

\begin{abstract}
This paper presents a study of tool wear and geometry response when machinability tests were applied under milling operations on the Super Austenitic Stainless Steel alloy AL-6XN. Eight milling trials were executed under two cutting speeds, two feed rates, and two depths of cuts. Cutting edge profile measurements were performed to reveal response of cutting edge geometry to the cutting parameters and wear. A scanning electron microscope (SEM) was used to inspect the cutting edges. Results showed the presence of various types of wear such as adhesion wear and abrasion wear on the tool rake and flank faces. Adhesion wear represents the formation of the built-up edge, crater wear, and chipping, whereas abrasion wear represents flank wear. The commonly formed wear was crater wear. Therefore, the optimum tool life among the executed cutting trails was identified according to minimum length and depth of the crater wear. The profile measurements showed the formation of new geometries for the worn cutting edges due to adhesion and abrasion wear and the cutting parameters. The formation of the built-up edge was observed on the rake face of the cutting tool. The microstructure of the built-up edge was investigated using SEM. The built-up edge was found to have the austenite shear lamellar structure which is identical to the formed shear lamellae of the produced chip.
\end{abstract}

\section{Introduction}

Super Austenitic Stainless Steel (SASS) AL-6XN alloy is a special type of Austenite Stainless Steel (ASS) distinguishable by its high alloying contents. High corrosion resistance of the alloy is gained by the presence of chromium, nickel, molybdenum, and nitrogen alloying elements. The alloying elements enhance the resistance of the alloy to stress corrosion cracking, crevices, and pitting corrosion. In addition, AL-6XN has high ductility, toughness, and strength, especially at elevated temperatures, compared to nominal austenitic grades. AL$6 \mathrm{XN}$ alloy is applied in various applications such as in offshore structures, chemical waste processing, food containers, transformer cases, and pumps parts [1]. The machinability of a material is a criterion used to define the ease with which the material can be machined [2]. Machinability of any work material depends on the properties of the material, the cutting tool material and geometry, the level of process parameters, and the machining environment (dry or wet machining) [2]. The machinability process is sensitive to the properties of the machined material, such as its strength, ductility, workhardening properties, and thermal conductivity. Therefore, ASS grades are characterised as poor machining materials [3].

A machinability study has been conducted by the authors of this work on the AL-6XN SASS alloy [4]. Eight cutting trials were executed under a combination of cutting parameters in a wet milling environment. The study explored the relationship between cutting parameters and machinability aspects such as the machined surface microhardness, roughness, and cutting forces. The variation in outcomes regarding cutting parameters showed how the AL-6XN SASS was a difficult-to-machine alloy. This paper aims to continue the machinability investigation of the AL-6XN SASS alloy using the wear analysis of the cutting tools. Twardowski et al. investigated the wear of milling cutting tools during machining of hardened steels alloys [5]. Their study showed the formation of flank wear which was used to estimate the life of the cutting edges. Also, a correlation between the applied cutting speed and the cutting tool life was studied to reveal cutting speed influences on the machinability process. Ghani 
et al. studied the machinability of Inconel 718 and Metal Matrix Composite (MMC) alloys using vertical and down milling operations [6]. Their study included the investigation of the formed wear on carbide cutting tool edges. Results showed an excessive failure due to formation of the builtup edge (BUE), flake, flank, and crater wear on the rake and flank faces. Also, researchers compared between the failures of the coated and uncoated carbide tools. When the coating of the cutting tool was removed through the machining process, the coated tool had a failure mode similar to that of the uncoated tool for the same applied cutting parameters. A milling machining process was applied by Shao et al. [7] on $12 \%$ Cr stainless steel alloy to study the wear of coated carbide tools. Their study showed that a low rake angle of $17^{\circ}$ increased tool life by reducing the formed wear, compared to a tool with a high rake angle of $28^{\circ}$. SEM was used to examine the edges and reveal the adhesive, abrasive, diffusive, and attrition wear and then correlated with the applied cutting parameters. Various wear types were noticed when the duplex stainless steel alloys were machined using a turning machine [8]. The BUE formation was formed on the rake face of the cutting tool when $150 \mathrm{~m} / \mathrm{min}$ cutting speed was used, whereas crater and flank wear on the edges of the cutting tool were created at $50 \mathrm{~m} / \mathrm{min}$ cutting speed. Earlier machinability studies have been conducted by researchers on different ASS grades [9-14]. A milling process was used to machine 316 AISI ASS alloy [9]. Flank, crater, and chipping wear were observed on the cutting tool edge. Flank wear was created when the tool coating was removed and chipping of the cutting edge occurred during the cutting process.

The austenitic stainless steel alloy type X5 CrMnN 18 18 has been machined using cemented carbide tools [10]; chipping and tool nose failure were detected using a scanning electron microscope. Tool life was found to be at its maximum value when a low cutting speed was used. However, tool life decreased whenever the cutting speed increased. Machinability in terms of single-point turning was applied on the AISI 304 ASS alloy [11]; results showed that, at $180 \mathrm{~m} / \mathrm{min}$ cutting speed, a decrease in flank wear on the tool cutting edge occurred. Furthermore, flank wear was found to be at its highest value when low cutting speeds were applied. Abou-ElHossein and Yahya [12] studied the machinability behaviour of AISI 304 ASS alloy. Coated carbide inserts were utilised in an end milling operation to cut the alloy. The main objective of the research was to assess the working efficiency of the inserts based on the wear and life of the cutting tool. The outcomes showed that when the feed rate increased, tool wear decreased. However, increasing the cutting speed led to increased tool wear. Furthermore, a BUE was formed on the cutting edge when a high feed rate and moderate cutting speed were applied. The machinability of AISI 304 and AISI 316 alloys was studied by Ciftici [13]. The cutting tool used to machine the alloy under turning operation was inspected and various wear types were identified. A correlation between wear and the cutting speed was explained. At high cutting speed, BUE formation decreased and the wear propagation increased, whereas, at low cutting speed, chipping wear formed on the cutting edge. Austenite Stainless Steel alloy of $18.5 \%$ chromium and $15.5 \%$ nickel was machined to study
TABLE 1: AL-6XN SASS chemical composition.

\begin{tabular}{lc}
\hline Element & Weight (\%) \\
\hline $\mathrm{C}$ & 0.02586 \\
$\mathrm{Si}$ & 0.3586 \\
$\mathrm{Mn}$ & 0.3696 \\
$\mathrm{P}$ & 0.0439 \\
$\mathrm{~S}$ & 0.00163 \\
$\mathrm{Cr}$ & 21 \\
$\mathrm{Mo}$ & 6.066 \\
$\mathrm{Ni}$ & 24 \\
\hline
\end{tabular}

the effect of the depth of cut on tool wear [14]. However, the outcomes showed no significant effects on wear rate when the depth of cut changed. Machinability of high performance ASS alloy of $21 \%$ chromium content was studied by Kim and Park [15]. Wear types such as notch and flank were observed on the cutting edge when a cutting speed of $100 \mathrm{~m} / \mathrm{min}$ was used. Also, a high cutting speed reduced the tool life and increased the propagation of the formed wear.

In the reviewed literature, wear investigations on machining various materials and alloys, including common ASS grades, have been conducted; however, a research gap exists in regard to the gradual progress of machining alloys progressing from ASS to SASS. To the best of our knowledge, machinability assessment due to tool wear analysis has not been studied on AL-6XN SASS alloy in machining field. Therefore, this paper's aim is to continue the authors' investigations on machinability of AL-6XN SASS alloy using tool wear analysis. This investigation consists of two parts. The first includes an observation analysis of tool wear using SEM according to the applied cutting parameters. The second part studies the geometry response of the cutting tool during the machining process. It is important in the machining field to establish the edge profile of the cutting tool, as this profile influences chip formation, performance, cutting tool life, and the thermal and mechanical loads created on the edges of the cutting tool during the machining process [16-18]. Wear and cutting edge geometry response regarding the alloy microstructure, as well as the applied cutting parameters, have been correlated in the presented outcomes.

\section{Materials and Methods}

2.1. Machined Material, Milling Parameters, and Milling Cutter. A spectrometry test was used to reveal the chemical composition of AL-6XN SASS alloy. Table 1 lists the significant alloying elements within the alloy microstructure.

The designation of the cutting trials was selected based on the authors' recently conducted work [4]. Eight milling trials were performed at two cutting speeds, two feed rates, and two depths of cuts as shown in Table 2. A proportional percentage of $(1: 10)$ phenol-water mixture was applied as a coolant during the cutting process.

A 5-axis SPINNER U620 CNC machining centre was used to execute the cutting trials. The specifications of the $\mathrm{CNC}$ machine were $15 \mathrm{~kW}$ spindle power and table diameter 




(a)

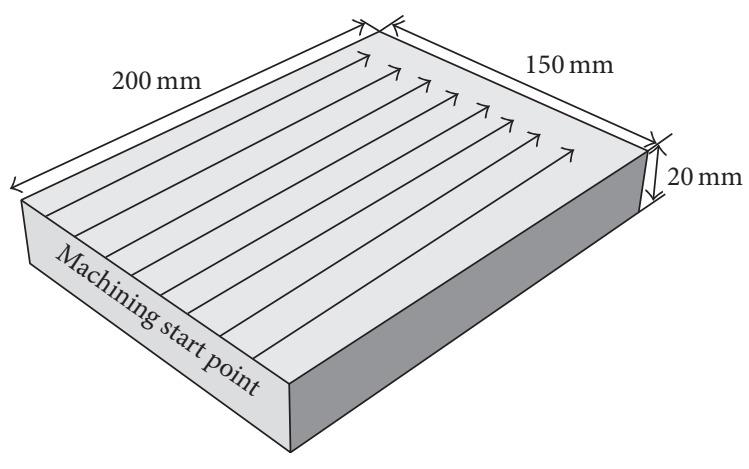

(b)

FIGURE 1: Dimensions and geometries of (a) milling cutter (cutting tool). (b) AL-6XN block.

TABLE 2: Arrangement of the cutting trials.

\begin{tabular}{lcccc}
\hline Trial & $\begin{array}{c}\text { Cutting speed } \\
(\mathrm{m} / \mathrm{min})\end{array}$ & $\begin{array}{c}\text { Feed/tooth } \\
(\mathrm{mm} / \text { tooth })\end{array}$ & $\begin{array}{c}\text { Cutting } \\
\text { depth }(\mathrm{mm})\end{array}$ & Coolant \\
\hline 1 & 100 & 0.1 & 2 & \\
2 & 100 & 0.1 & 3 & \\
3 & 100 & 0.15 & 2 & \\
4 & 100 & 0.15 & 3 & On \\
5 & 150 & 0.1 & 2 & \\
6 & 150 & 0.1 & 3 & \\
7 & 150 & 0.15 & 2 & \\
8 & 150 & 0.15 & 3 & \\
\hline
\end{tabular}

of $650 \mathrm{~mm}$. An ISCAR HELIDO 490-09 insert of cutting grade IC830 was used during the machining test. The cutting insert designation standard is H490 ANCX 090416PDR and has dimensions and geometry as provided by the manufacturer's data as shown in Figure 1(a). This type of the cutting insert is used for rough and hard machining applications, and the cutting insert has four cutting edges and a nose radius of $0.8 \mathrm{~mm}$. The AL-6XN alloy, which has dimensions and geometry as shown in Figure 1(b), was fixed on the stage of the CNC machine and a side-by-side cutting process was executed as shown in Figure 2. During the test, the cutting edge was replaced after each cutting process and a new cutting edge was used per trial to preserve zero reference tool wear condition. The actual cutting time was equal to 20 seconds per trial, and eight cutting trials were formed.

\subsection{Tool Wear Inspection Using Scanning Electron Microscope.} A Zeiss Supra 55VP SEM was used to inspect the edges of the cutting inserts (Figure 3). The applied electron microscope settings were $20 \mathrm{kV}, 10 \mathrm{~mm}$ working distance, high current mode on, and $60 \mu \mathrm{m}$ aperture size. SEM images of the cutting tool revealed the presence of wear and BUE on the cutting edges. The cutting tools used for the scanning process were washed by ethanol and dried to remove dirt. These tools were then mounted on the SEM stage and vacuumed at high pressure to avoid electron beam scattering during scanning.
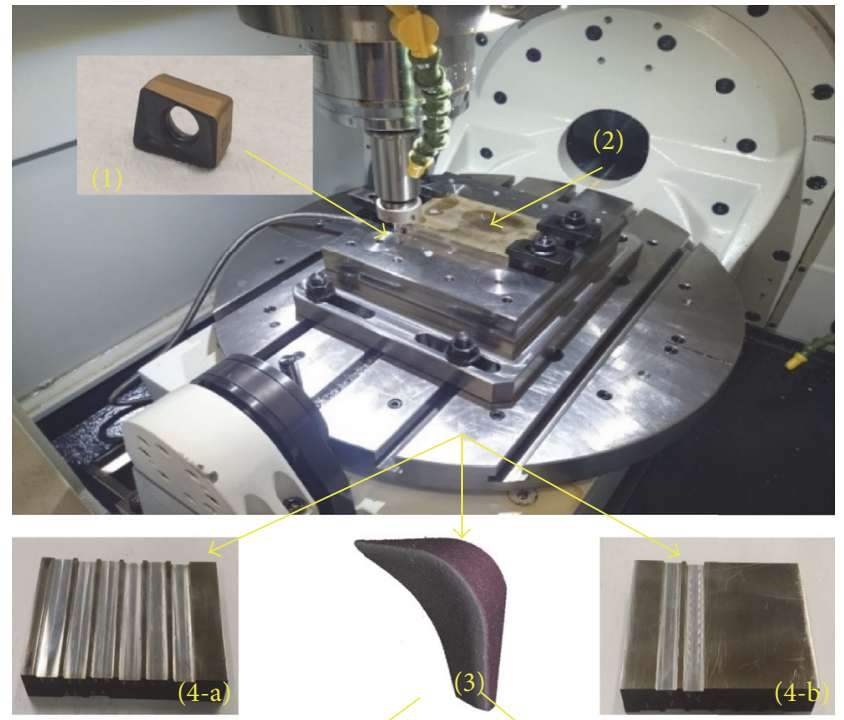

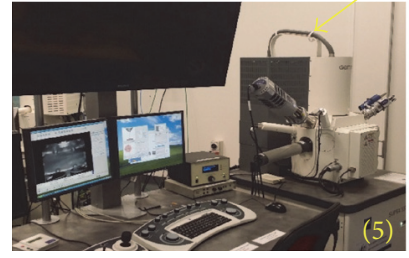

(1) Cutting tool.

(2) Mounted workpiece on the stage of the milling machine.

(3) Edges of the cutting tool.



(4) Eight machined bays ( $a$ and $b$ ). (6) Alicona optical profilometer. (5) Scanning electron microscope.

FigURE 2: Experimental setup.

A Secondary Electron (SE) detector was used in this work to scan all the samples.

2.3. Tool Wear Measurements Using InfiniteFocus Optical Profilometer. An Alicona InfiniteFocus (AIF) optical profilometer was used to scan the profile of the cutting edge. More details about the technical specification and scanning process using AIF are available online [19]. The cutting insert 


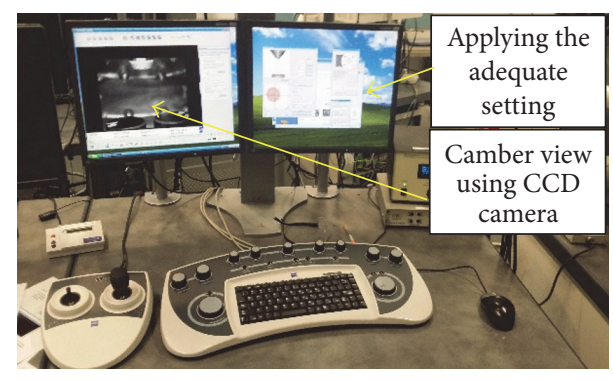

(a)

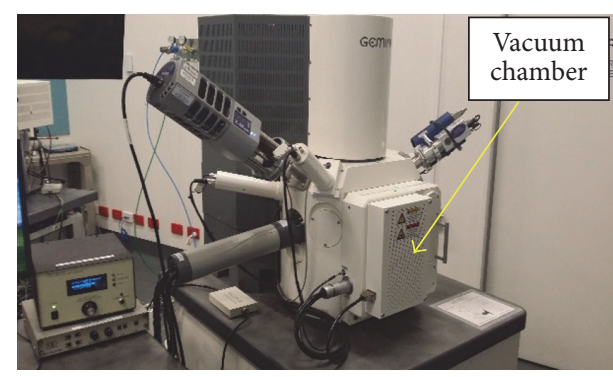

(b)

FIGURE 3: SEM system. (a) Monitors and joysticks used to apply the adequate settings. (b) SEM vacuum chamber.
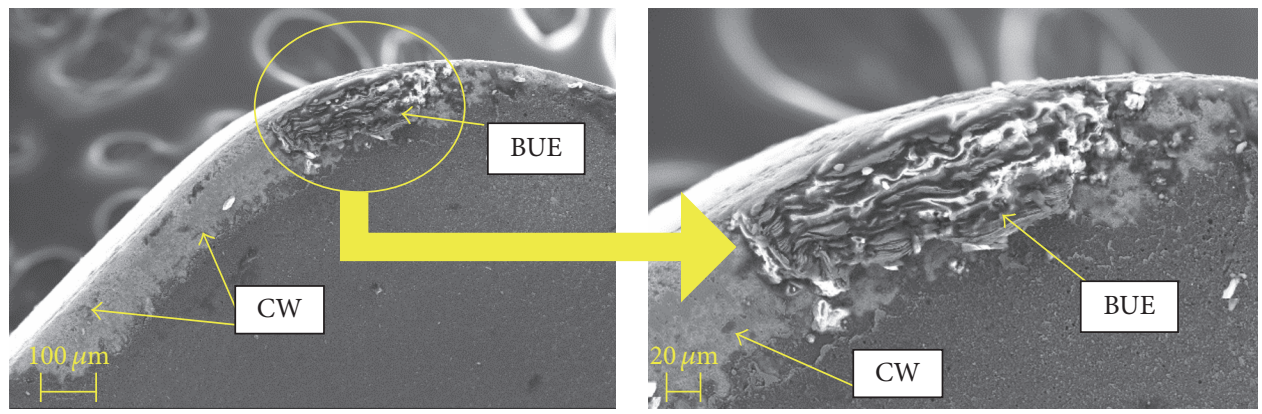

FIGURE 4: SEM images of the cutting insert of trial 5 revealing wear and BUE formation.
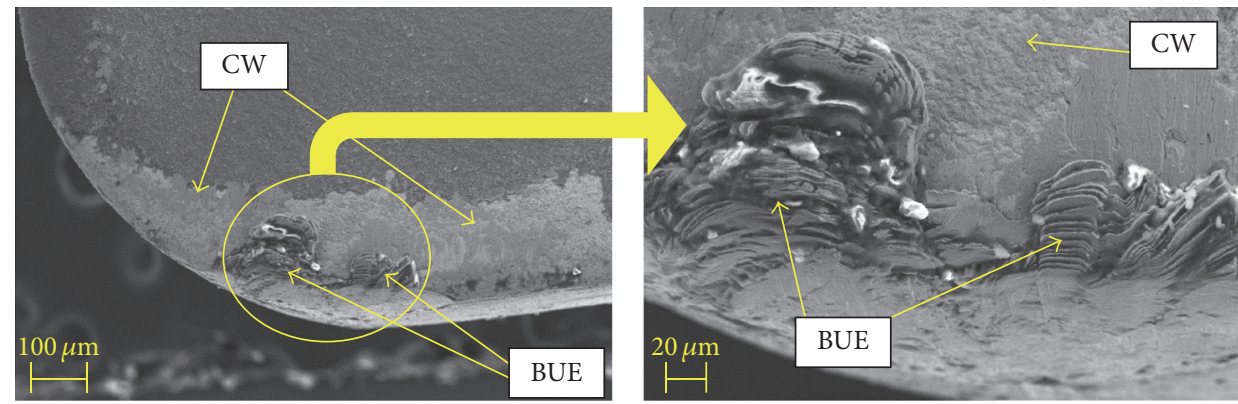

FIGURE 5: SEM images of the cutting insert of trial 7 revealing wear and BUE formation.

was fixed on the stage of the AIF device and profile measurements analyses were conducted using IF-MeasureSuite 5.1 software to reveal the geometries of the cutting edges. This process was used in a previous machining study by Królczyk et al. [20]. The AIF 3D optical profilometer is considered to be a new technique to evaluate the surface profiles of the cutting tools. The profilometer is a noncontact imager device measuring the depth of the edges based on a focus variation process. The benefit of using an optical imager is obtaining precise measurements without causing any surface damage, as with other methods, where the tool must be sectioned, prepared, and scanned by SEM and where profiles can only be approximately calculated [17, 21]. The relationship between the geometry of the cutting edges and effects of the cutting parameters, as well as with the generated wear and BUE, could be analysed throughout the profile measurement study.

\section{Results and Discussion}

3.1. Tool Wear and Built-Up Edge Investigation Using Scanning Electron Microscope. The edges of the cutting inserts were examined under the SEM detector to reveal the presence of the BUE. The BUE formation was identified on the rake faces of cutting inserts 5 and 7, respectively, as shown in Figures 4 and 5. In these two trials, a high cutting speed of $150 \mathrm{~m} / \mathrm{min}$ and high depth of cut of $3 \mathrm{~mm}$ were used. When the depth of cut increased, the thickness of the removed cutting section facing the cutting edge will increase. As a consequence, the generated temperature due to the cutting process will be elevated at the rake face. Also, a high cutting speed reduces the time to dissipate the temperature during the cutting process, and material plastic flow resulted $[22,23]$. In addition, because the AL-6XN SASS alloy is characterised by its low thermal conductivity, the temperature value in the shear zone will create a welding process between the 




(a)

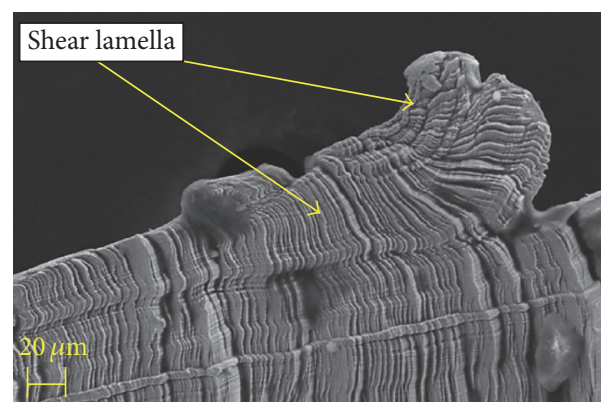

(b)

FIGURE 6: (a) Inspection of the microstructure of the formed BUE in trial 7. (b) Inspection of the formed chip of trial 7 to make a comparison with the microstructure of the BUE.

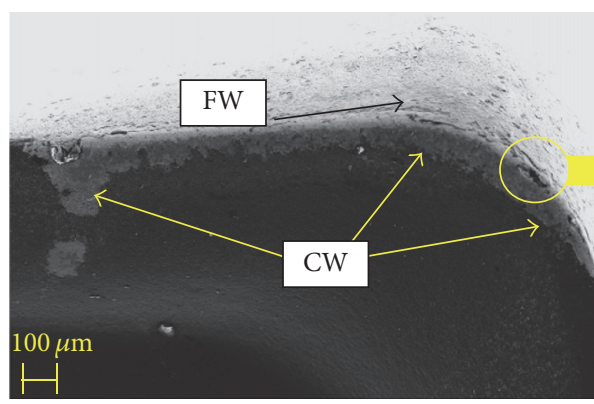

(a)

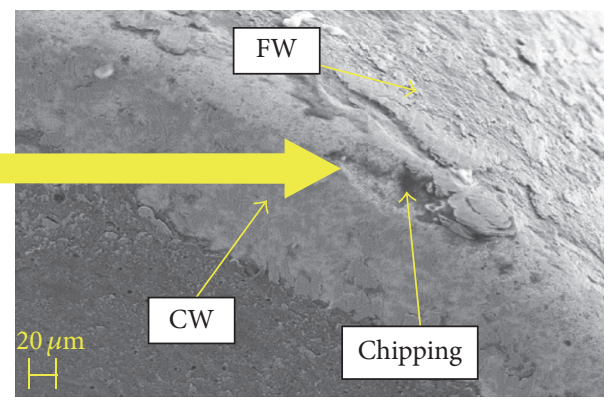

(b)

FIGURE 7: SEM images of the cutting insert of trial 6 to reveal wear types.

cutting edge and the removed material to form the BUE. It was reported by Krolczyk et al. [8] that the combination of cutting speed and feed rate has a significant influence on the formation of the BUE. Their results showed that, at high cutting speed of $150 \mathrm{~m} / \mathrm{min}$ and large feed, a large BUE was spread on the rake face of the cutting tool.

When the BUE was examined under the SEM detector, the BUE was found to consist of austenite shear lamellae. Figure 6(a) shows the accumulation of the shear lamellae on the insert rake face to form the BUE. The chip produced from the cutting process in trial 7 was also examined using the SEM detector, as shown in Figure 6(b). The produced chip was found to have the same structure (shear lamellae) that appeared in the BUE microstructure which resulted due to the slipping mechanism, shearing, and fracturing behaviour during the cutting process, as reported in other studies [24, 25]. However, the adhering wear presented by the formation of the BUE on the rake face of the cutting tool leads to the formation of the crater wear (CW), flank wear (abrasion wear), and chipping when the machining process proceeds, as the BUE particles are not stable and can easily be subtracted from the hosting surfaces [26].

Figure 7 shows the SEM image of the cutting edge for trial 6, which is opposite to the cutting edge used in trial 5 . From this image, the CW, flank wear (FW), and chipping are evident. The extent of the CW is higher compared to the FW on the cutting edges. This can be related to the effect of the flood coolant and the cutting time during the



FIGURE 8: SEM image of the chip cross section which reveals the presence of carbides and the adhered particles causing FW on the insert's flank faces.

machining process. According to Ezugwu et al. [27] and Ezugwu and Bonney [28], the applied coolant can penetrate the workpiece-cutting tool contacting area, reducing the friction and hence decreasing the temperature at the shear zone. These coolant effects strengthen the flank edge and eradicate the abrasive wear $(\mathrm{FW})$ to a certain extent. Figure 8 shows the located carbides and very small adhered cutting tool particles on the edge of the formed chip.

In Figure 8, it can be seen that very small particles were separated from the cutting tool and adhered to the backside of the formed chip. When this chip flows against the cutting tool, the adhered particles work as abrading elements to crater the rake face of the cutting tool. This fact was also 


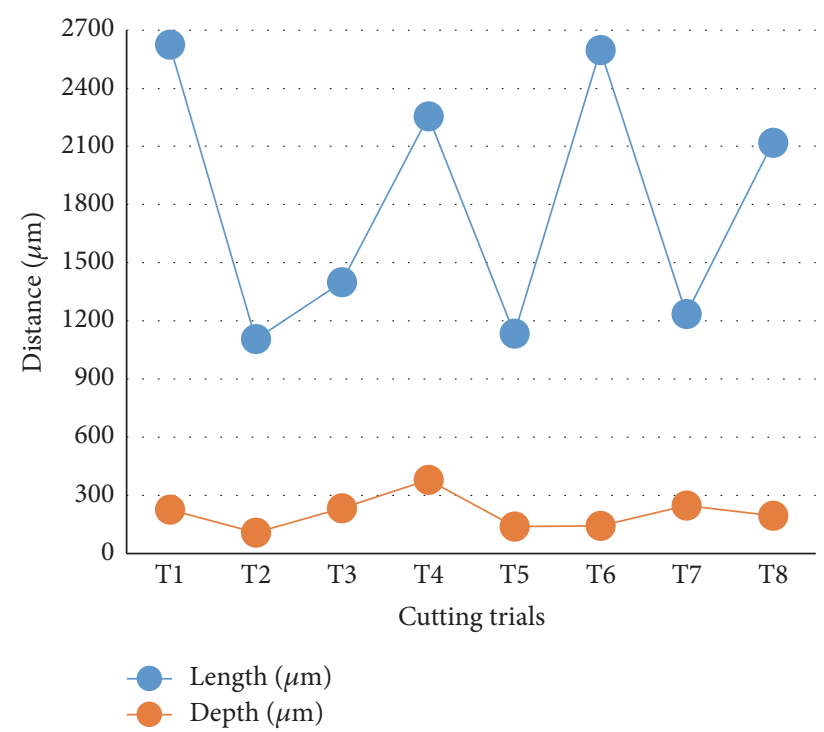

FIGURE 9: Estimation of the length and the depth of CW formed on the cutting edges of the eight cutting trials.

proven in a recently conducted machining study by Rahman Rashid et al. [23]. The chipping wear was formed at the cutting wedge of the cutting tool. The reason behind the chipping is the separation of the welded BUE, which causes the occurrence of pitting and surface subtraction, which is similar to the reported findings in another study [6]. Another cause reported in literature states that a high cutting speed and improperly selected cooling method caused vibrations during machining, which in turn exposed the cutting tool to cyclic loads creating thermal cracks (fatigue cracks) and, as a result, chipping occurred [29]. Due to size limitations, only SEM images of the cutting insert of trial 6 were cited in Figure 6 to display the various types of wear.

Generally, FW was detected on the cutting edges of the eight cutting trials but with low values. However, when a high cutting speed of $150 \mathrm{~m} / \mathrm{min}$ was applied, the FW of cutting trials 5-8 was smaller compared to the FW in the cutting trials $1-4$, where a low speed of $100 \mathrm{~m} / \mathrm{min}$ was used. When high feed of $0.15 \mathrm{~mm} /$ tooth was used in trials 3 and 7 , the depth of FW increased. The effects of the depth of cut on FW were noticed and studied in trials 2, 3, and 7. When the depth of cut value was changed from $3 \mathrm{~mm}$ in trial 2 to $2 \mathrm{~mm}$ in trial 3, FW increased, which was the same effect when the depth of cut of $2 \mathrm{~mm}$ was used in trial 7. The FW on the flank faces of the cutting inserts was probably induced due to the presence of the formed carbides in the alloy microstructure during the cutting process, as shown in Figure 8 . Such carbides are considered harmful particles to cutting tools as the carbides are hard and brittle elements that cause and increase wear. In early studies, researchers found that shear stress and normal stress were increased at the tool tip which can cause a softening phenomenon on the cutting edges due to increasing temperature and promote wear formation during the cutting process [30-32].

It can be seen from Figures $4-7$ that $\mathrm{CW}$ is the most significant type of wear produced during the cutting process.
Therefore, the tool life in this study was represented according to the length and the depth of CW. Accordingly, SEM images were captured for the rake faces of all cutting inserts to evaluate the length and the depth of CW. Such results aim to provide a concept of $\mathrm{CW}$ formation and distribution on the rake faces in relation to applied cutting conditions; thus, it can be concluded that more CW was generated than FW. Therefore, measurements of CW were performed and are listed and shown in Figure 9. The maximum length for CW $(2624 \mu \mathrm{m})$ was located in trial 1 , where the lowest feed and depth of cut were used. The largest depth of CW $(380 \mu \mathrm{m})$ was found when the feed rate was increased in trial 4 . From Figure 9, the extent of CW was reduced in length and depth by $58 \%$ and $71 \%$, respectively, at a low cutting speed when the depth of cut was increased to $3 \mathrm{~mm}$ in trial 2 . This confirms that longer life for cutting tools will be gained when the cutting parameters of trial 2 are used, whereas shorter life was obtained at trials 1 and 4 , where the maximum CW length and depth were recorded, respectively.

3.2. Profile Measurements of Cutting Tool Edges. The cutting inserts were subjected to profile measurement analysis using IF-MeasureSuite 5.1 software to determine the relationship between tool geometry and wear and with cutting parameters. The changes in the cutting tool geometry, locations of the wear, and BUE were shown through this analysis. The profile of the new cutting edge was measured first to indicate the positions of the tool tip and rake and flank faces; then the measurements were applied on the eight worn cutting edges to view the new shaped profiles as presented in Figure 10.

The effects of the FW and CW were found on the flank and rake faces, respectively, of the eight cutting inserts. Chipping wear significantly affected the geometries of the cutting inserts used in trials 3,4 , and 8 by lowering cutting edges. Sharp and long edges were formed on the inserts' rake faces in trials 5 and 7 due to the presence of the BUE.

At the low cutting speed and low feed rate in trials 1 and 2, the cutting edges were worn and their locations were shifted to the right of the reference edges (Figure 9). At low cutting speed and high feed rate, the cutting edges were severely deformed and new (secondary) cutting edges were created. At high cutting speed and low depth of cut (trials 5 and 7), the newly created edges had additional height compared to the old edges according to the formed BUE, whereas in trials 6 and 8 (high depth of cut) the new cutting edge locations were lowered and shifted to the right due to crater and chipping wear.

It can be summarised from the profile measurements of the cutting tool edges that the newly formed profiles affected the obtained results from the authors' preliminary machining study [4]. The roughness values of the machined surfaces deteriorated due to the machining with cutting inserts of nonuniform profiles of the cutting edges. Moreover, the tips of the cutting inserts were greatly deformed, which in turn increased the roughness of the machined surfaces. This effect could be noticed by observing the radius status of the cutting tip between the rake and flank faces $[16,18]$. The cutting tip radius of the new cutting insert (Figure 10: new) was significantly increased due to lowering the cutting wedge as 

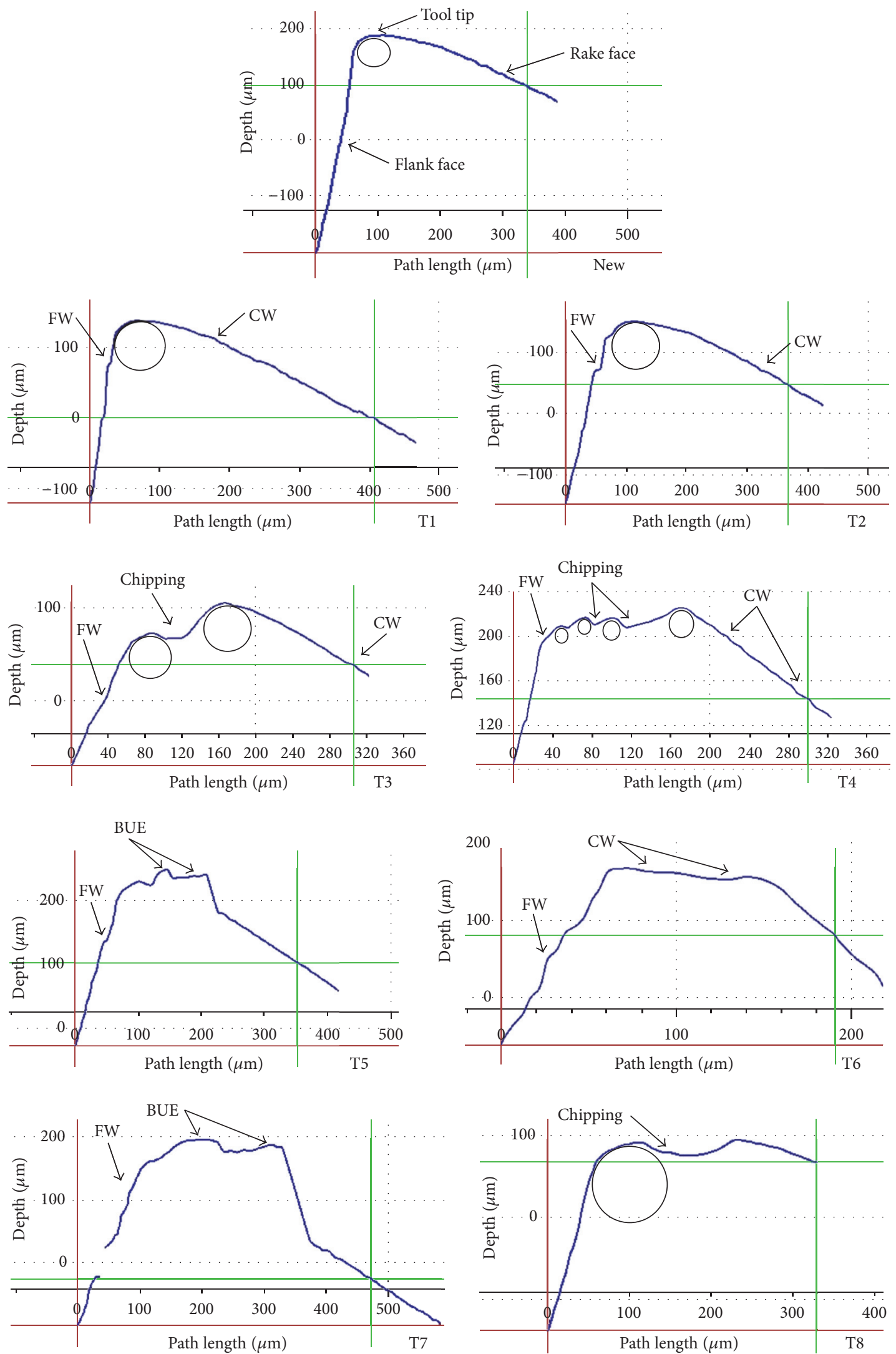

Figure 10: Cutting tool path profile estimation for the new and worn cutting edges with respect to the applied cutting conditions and the generated FW, CW, chipping, and BUE. 
shown in Figure 10: T1, T2, and T8. Two rounded edges of different radii were formed due to the chipping wear in trial 3 , whereas four edges were located on the cutting edge in trial 4 due to severe chipping. In trials 5 and 7 , the rounded edges were excessively deformed and edges with sharp angles were created. Finally, a long and flat (chamfered) edge due to CW resulted on the cutting edge in trial 6 . Also, the worn cutting edges of the new profiles increased the noise, chatter, and vibration during the cutting process, which was also detected in another study [33], which influenced the obtained cutting forces.

\section{Conclusion}

In this work, eight cutting trials were conducted using a milling machine on AL-6XN SASS alloy to study wear and geometry response of cutting tools to the applied cutting parameters. The main outcomes are as follows.

(1) Abrasive and adhesive wear types were identified on the cutting tool edges using SEM. FW and CW represented abrasive wear, whereas the adhered BUE represented adhesive wear. The located carbides and the adhered small pieces of the cutting edges on the backside of the formed chip motivated and increased the spread of FW and FW, respectively, when the chip slipped on the tool during the cutting process.

(2) Chipping wear was recognised on the cutting wedge of the cutting tool. This wear was created due to the surface subtraction phenomenon found in machining when a BUE is evident. The BUE is an unstable adhered layer that can be separated easily from the hosting surfaces and causes pitting and microcracks which are the chipping wear motivation.

(3) The common wear in this study was CW. Therefore, the dimensions of CW (length and depth) were used to find the optimum life of the eight cutting tools. The length and the depth of CW were calculated. Maximum length and depth of $2624 \mu \mathrm{m}$ and $380 \mu \mathrm{m}$ were obtained in trials 1 and 4, respectively. The length and the depth of the crater wear were decreased up to $58 \%$ and $71 \%$, respectively, in trial 2 , where a low speed and feed with high depth of cut were applied. Therefore, the optimum life of the cutting tool was selected for trial 2.

(4) Trials 5 and 7, where the high cutting speed, depth of cut, and low feed rate were applied, showed a significant BUE formation on the rake faces of the cutting inserts. The BUE microstructure was inspected and found to be similar to the microstructure of the formed chip due to material plastic flow and chip slip mechanism during machining.

(5) Profile measurements of the cutting tool edges were executed to reveal the geometry response of the cutting edges to the applied cutting parameters as well as to the generated wear types, BUE, and roughness values. At low cutting speed in trials $1-4$, the cutting edges were shifted to the right and their heights were changed. At high cutting speeds in trials 5-8, the cutting edges were severely deformed and new sharp, shifted edges were generated.

(6) The tip radii of the cutting inserts were changed according to wear type. Large radii were identified when the cutting wedge was lowered in trials 1 , 2 , and 8. Two large and four small rounded edges were formed due to chipping wear in trials 3 and 4, respectively. BUE formation resulted in edges of sharp angles in trials 5 and 7, whereas CW on the cutting edge of trial 6 formed a long and flat (chamfered) edge.

(7) For workshop practice, these concluding results can serve as reference data to predict tool life and to machine SASS using cutting parameters which best avoid aggressive tool wear and frequent BUE formation.

\section{Competing Interests}

The authors declare that there are no competing interests regarding the publication of this paper.

\section{References}

[1] R. B. Flores, A. Ruíz, C. Rubio-González et al., "Effect of heat input and accumulated fatigue damage on mechanical properties of dissimilar AL-6XN/316L welded joints," Materials Characterization, vol. 112, pp. 41-50, 2016.

[2] S. Kalpakjian and S. R. Schmid, Manufacturing Engineering and Technology, Pearson, Upper Saddle River, NJ, USA, 2014.

[3] M. P. Groover, Fundamentals of Modern Manufacturing: Materials, Processes, and Systems, John Wiley \& Sons, New York, NY, USA, 2007.

[4] A. Polishetty, M. F. A. Alabdullah, N. Pillay, and G. Littlefair, "A preliminary study on machinability of super austenitic stainless steel," in Proceedings of the ASME International Mechanical Engineering Congress and Exposition, American Society of Mechanical Engineers, Houston, Tex, USA, November 2015.

[5] P. Twardowski, S. Legutko, G. M. Krolczyk, and S. Hloch, "Investigation of wear and tool life of coated carbide and cubic boron nitride cutting tools in high speed milling," Advances in Mechanical Engineering, vol. 7, no. 6, pp. 1-9, 2015.

[6] J. A. Ghani, C. H. Che Haron, M. S. Kasim, M. A. Sulaiman, and S. H. Tomadi, "Wear mechanism of coated and uncoated carbide cutting tool in machining process," Journal of Materials Research, vol. 31, no. 13, pp. 1873-1879, 2016.

[7] H. Shao, L. Liu, and H. L. Qu, "Machinability study on 3\%Co$12 \%$ Cr stainless steel in milling," Wear, vol. 263, no. 1-6, pp. 736744, 2007.

[8] G. M. Krolczyk, P. Nieslony, and S. Legutko, "Determination of tool life and research wear during duplex stainless steel turning," Archives of Civil and Mechanical Engineering, vol. 15, no. 2, pp. 347-354, 2015.

[9] M. Nordin, R. Sundström, T. I. Selinder, and S. Hogmark, "Wear and failure mechanisms of multilayered PVD TiN/TaN coated tools when milling austenitic stainless steel," Surface and Coatings Technology, vol. 133-134, pp. 240-246, 2000. 
[10] J. Paro, H. Hänninen, and V. Kauppinen, “Tool wear and machinability of X5 CrMnN 1818 stainless steels," Journal of Materials Processing Technology, vol. 119, no. 1-3, pp. 14-20, 2001.

[11] I. Korkut, M. Kasap, I. Ciftci, and U. Seker, "Determination of optimum cutting parameters during machining of AISI 304 austenitic stainless steel," Materials and Design, vol. 25, no. 4, pp. 303-305, 2004.

[12] K. A. Abou-El-Hossein and Z. Yahya, "High-speed end-milling of AISI 304 stainless steels using new geometrically developed carbide inserts," Journal of Materials Processing Technology, vol. 162-163, pp. 596-602, 2005.

[13] I. Ciftci, "Machining of austenitic stainless steels using CVD multi-layer coated cemented carbide tools," Tribology International, vol. 39, no. 6, pp. 565-569, 2006.

[14] V. P. Astakhov, "Effects of the cutting feed, depth of cut, and workpiece (bore) diameter on the tool wear rate," International Journal of Advanced Manufacturing Technology, vol. 34, no. 7-8, pp. 631-640, 2007.

[15] S.-T. Kim and Y.-S. Park, "Effects of copper and sulfur additions on machinability behavior of high performance austenitic stainless steel," Metals and Materials International, vol. 15, no. 2, pp. 221-230, 2009.

[16] S. N. Oliaei and Y. Karpat, "Investigating the influence of built-up edge on forces and surface roughness in micro scale orthogonal machining of titanium alloy Ti6Al4V," Journal of Materials Processing Technology, vol. 235, pp. 28-40, 2016.

[17] S. Sun, M. Brandt, S. Palanisamy, and M. S. Dargusch, "Effect of cryogenic compressed air on the evolution of cutting force and tool wear during machining of Ti-6Al-4V alloy," Journal of Materials Processing Technology, vol. 221, pp. 243-254, 2015.

[18] B. Denkena and D. Biermann, "Cutting edge geometries," CIRP Annals-Manufacturing Technology, vol. 63, no. 2, pp. 631-653, 2014.

[19] Alicona, Alicona Infinite Focus 3D Optical Profilometer, 2016, http://www.alicona.com/products/infinitefocus/.

[20] G. Królczyk, S. Legutko, and P. Raos, "Cutting wedge wear examination during turning of duplex stainless steel," Tehnicki Vjesnik, vol. 20, no. 3, pp. 413-418, 2013.

[21] Y.-L. Chen, Y. Cai, Y. Shimizu, S. Ito, W. Gao, and B.-F. Ju, "On-machine measurement of microtool wear and cutting edge chipping by using a diamond edge artifact," Precision Engineering, vol. 43, pp. 462-467, 2016.

[22] J. Zhou, V. Bushlya, P. Avdovic, and J. E. Ståhl, "Study of surface quality in high speed turning of Inconel 718 with uncoated and coated CBN tools," The International Journal of Advanced Manufacturing Technology, vol. 58, no. 1-4, pp. 141-151, 2012.

[23] R. A. Rahman Rashid, S. Palanisamy, S. Sun, and M. S. Dargusch, "Tool wear mechanisms involved in crater formation on uncoated carbide tool when machining Ti6Al4V alloy," International Journal of Advanced Manufacturing Technology, vol. 83, no. 9-12, pp. 1457-1465, 2015.

[24] A. I. Fernández-Abia, J. Barreiro, L. N. L. D. Lacalle, and S. Martínez, "Effect of very high cutting speeds on shearing, cutting forces and roughness in dry turning of austenitic stainless steels," The International Journal of Advanced Manufacturing Technology, vol. 57, no. 1-4, pp. 61-71, 2011.

[25] G. Manimaran and M. Pradeep Kumar, "Effect of cryogenic cooling and sol-gel alumina wheel on grinding performance of AISI 316 stainless steel," Archives of Civil and Mechanical Engineering, vol. 13, no. 3, pp. 304-312, 2013.
[26] V. T. G. Naves, M. B. Da Silva, and F. J. Da Silva, "Evaluation of the effect of application of cutting fluid at high pressure on tool wear during turning operation of AISI 316 austenitic stainless steel," Wear, vol. 302, no. 1-2, pp. 1201-1208, 2013.

[27] E. O. Ezugwu, R. B. Da Silva, J. Bonney, and Á. R. MacHado, "Evaluation of the performance of CBN tools when turning Ti$6 \mathrm{Al}-4 \mathrm{~V}$ alloy with high pressure coolant supplies," International Journal of Machine Tools and Manufacture, vol. 45, no. 9, pp. 1009-1014, 2005.

[28] E. O. Ezugwu and J. Bonney, "Effect of high-pressure coolant supply when machining nickel-base, Inconel 718, alloy with coated carbide tools," Journal of Materials Processing Technology, vol. 153-154, no. 1-3, pp. 1045-1050, 2004.

[29] R. B. Da Silva, J. M. Vieira, R. N. Cardoso et al., "Tool wear analysis in milling of medium carbon steel with coated cemented carbide inserts using different machining lubrication/cooling systems," Wear, vol. 271, no. 9-10, pp. 2459-2465, 2011.

[30] E. O. Ezugwu, "Key improvements in the machining of difficultto-cut aerospace superalloys," International Journal of Machine Tools and Manufacture, vol. 45, no. 12-13, pp. 1353-1367, 2005.

[31] A. Richetti, Á. R. Machado, M. B. Da Silva, E. O. Ezugwu, and J. Bonney, "Influence of the number of inserts for tool life evaluation in face milling of steels," International Journal of Machine Tools and Manufacture, vol. 44, no. 7-8, pp. 695-700, 2004.

[32] E. M. Trent and P. K. Wright, Metal Cutting, ButterworthHeinemann, 2000.

[33] B. S. Prasad, M. P. Babu, and Y. R. Reddy, "Evaluation of correlation between vibration signal features and three-dimensional finite element simulations to predict cutting tool wear in turning operation," Proceedings of the Institution of Mechanical Engineers, Part B: Journal of Engineering Manufacture, vol. 230, no. 2, pp. 203-214, 2016. 




\section{Enfincering}
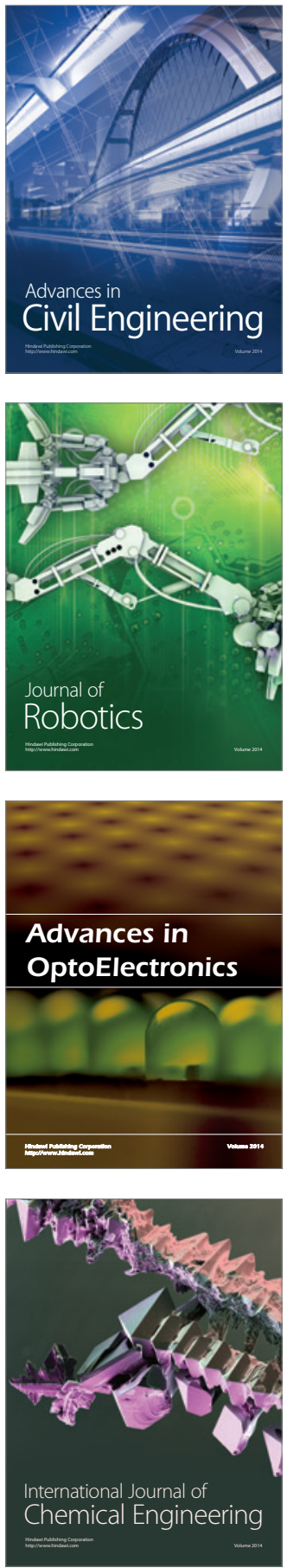

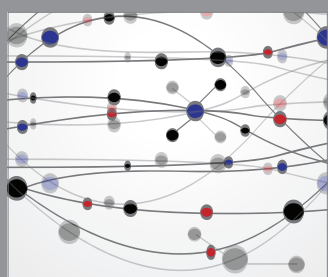

The Scientific World Journal

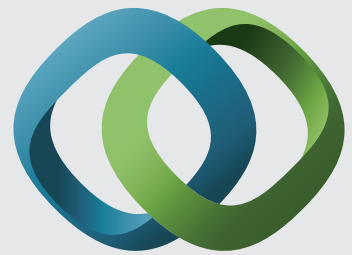

\section{Hindawi}

Submit your manuscripts at

http://www.hindawi.com
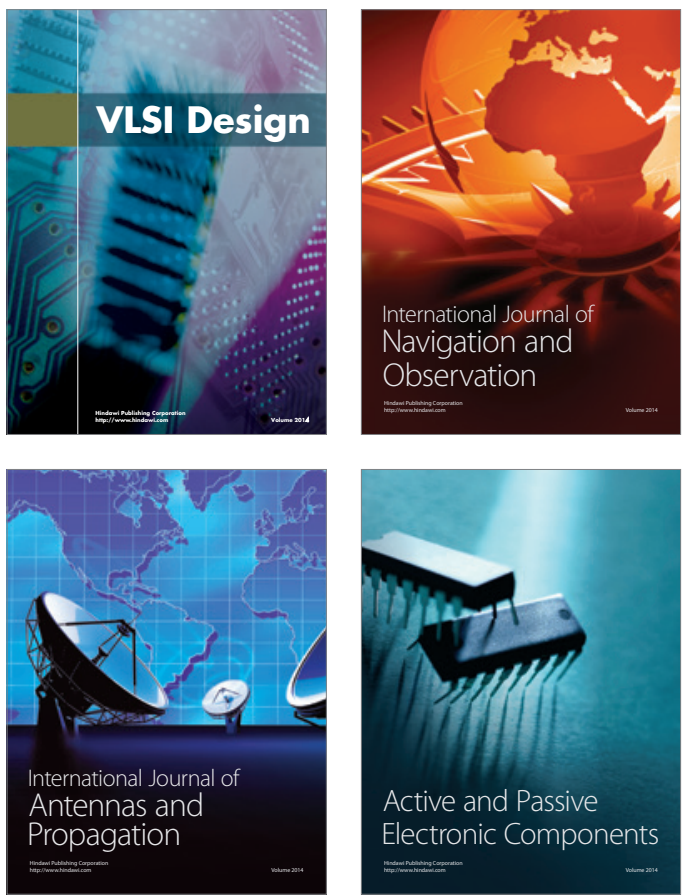
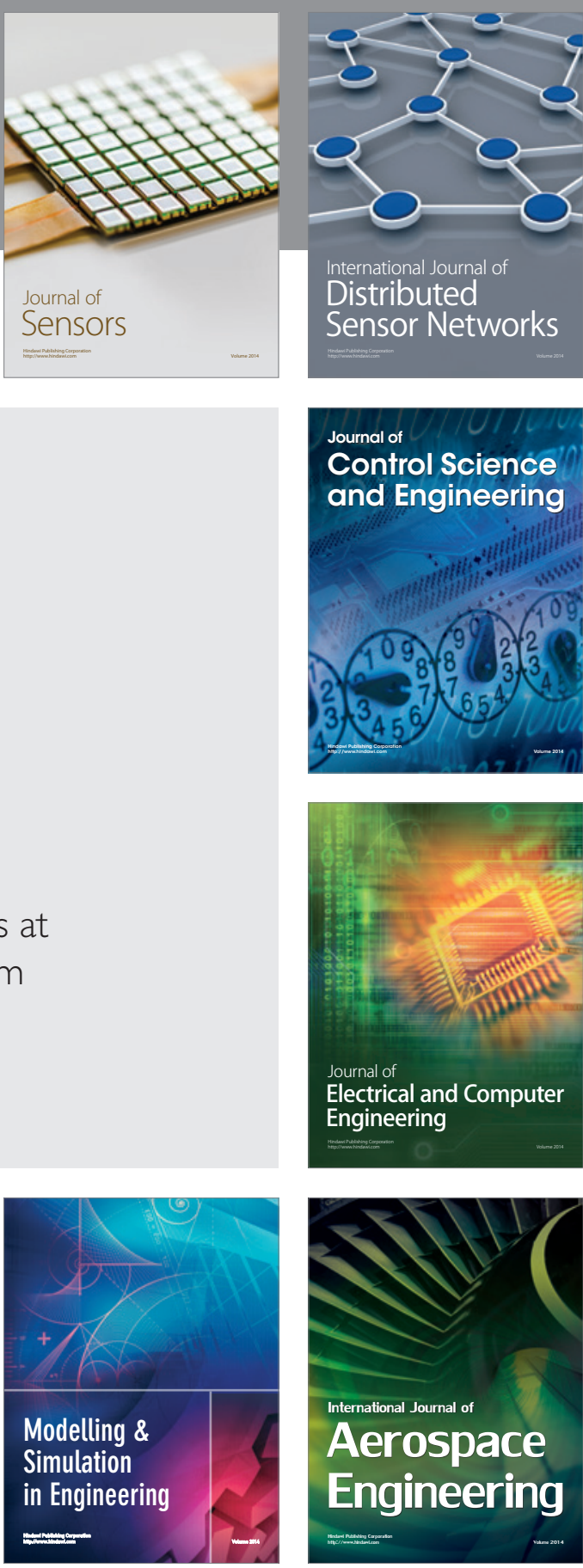

International Journal of

Distributed

Sensor Networks

Journal of

Control Science

and Engineering
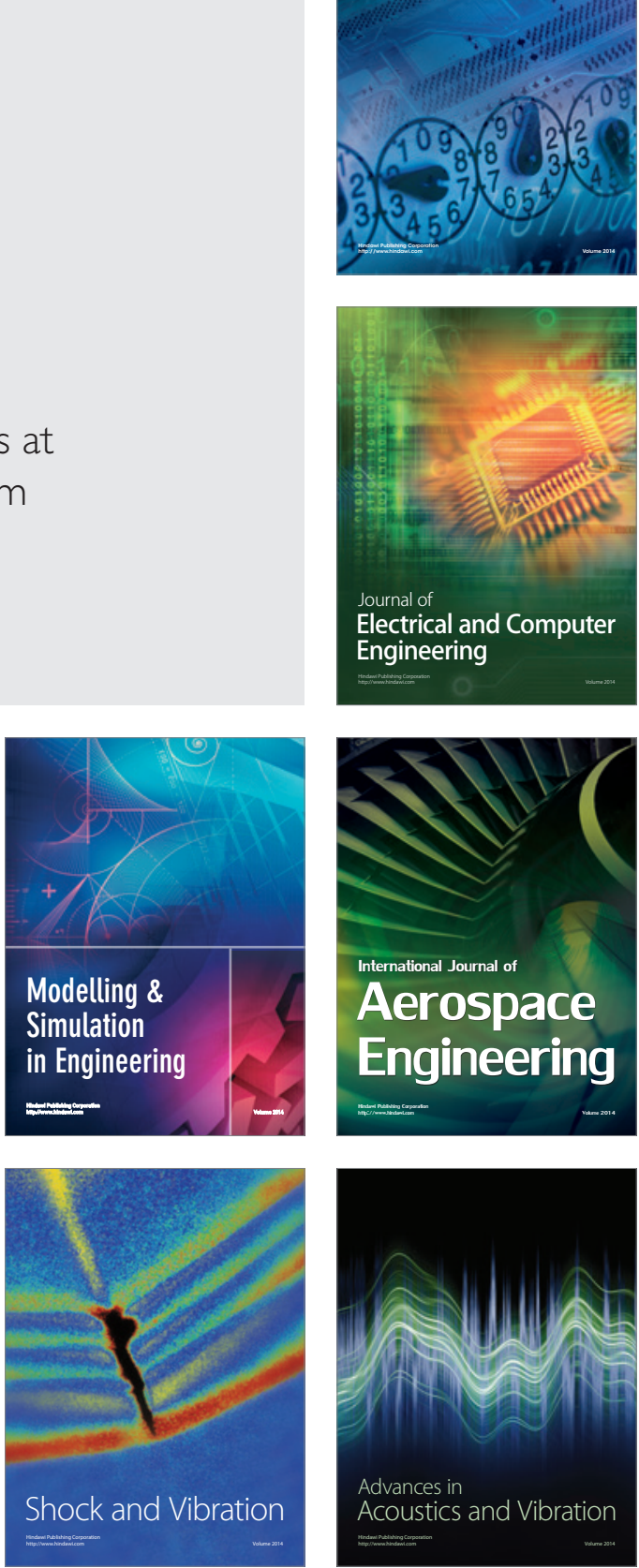